\title{
QUASI-ADJOINT THIRD ORDER DIFFERENCE EQUATIONS: OSCILLATORY AND ASYMPTOTIC BEHAVIOR
}

\author{
B. SMITH \\ Department of Mathematics \\ Texas Southern University \\ Houston, Texas 77004 U.S.A. \\ (Received August 6, 1985)
}

ABSTRACT. In this paper, asymptotic properties of solutions of

$$
\Delta^{3} v_{n}+P_{n-1} v_{n+1}=0
$$

are investigated via the quasi-adjoint equation

$$
\Delta^{3} U_{n}-P_{n} U_{n+2}=0 \text {. }
$$

A necessary and sufficient condition for the existence of oscillatory solutions of (E+) is given. An example showing that it is possible for (E+) to have only nonoscillatory solutions is also given.

KEY WORDS AND PHRASES. Difference equations, third order, oscillatory and nonoscillatory solutions, quasi-adjoint equations.

1980 AMS SUBJECT CLASSIFICATION CODES. 39A10, $39 A 12$.

1. INTRODUCTION.

This study is concerned with the solutions of $(E+)$, where $\Delta$ denotes the forward differencing operation $\Delta V_{n}=V_{n+1}-V_{n}$. The coefficient function is a real sequence satisfying $P_{n-1}>0$ for each $n \geq 1$. By the graph of a solution $V=\left\{v_{n}\right\}$ we mean the polygonal path connecting the points $\left(n, v_{n}\right), n \geq 1$. A point of contact of the graph of $V$ with the real axis is a node. A solution $V$ of (E+) is said to be osc11latory if it has arbitrarily large nodes; otherwise it is said to be nonoscillatory. Hereafter the term "solution" shall mean "nontrivial solution".

The oscillation criterion established by Lazer [1, Theorem 1.2], for the differential equation $y^{\prime \prime \prime}+p(x) y^{\prime}+q(x) y=0$, where $p(x) \leq 0, q(x)>0$ is proved for the difference equation $(E+)$. We also include an example which demonstrates that is possible for $(E+)$ to have only nonoscillatory solutions.

In studying $(\mathrm{E}+)$ we will make use of its quasi-adjoint equation (E-). For general properties and definitions concerning $(E+)$ and $(E-)$ we refer to Fort's book [2], and to the paper by this author.

2. PRELIMINARY RESULTS.

Equation (E-) always has a nonoscillatory solution. In fact, (E-) has a solution which satisfies 


$$
\mathrm{U}_{\mathrm{n}} \Delta \mathrm{U}_{\mathrm{n}} \Delta^{2} \mathrm{U}_{\mathrm{n}} \neq 0, \mathrm{U}_{\mathrm{n}}>0, \Delta \mathrm{U}_{\mathrm{n}}>0, \Delta^{2} \mathrm{U}_{\mathrm{n}}>0 \text {, }
$$

for all $n$ sufficiently large (see [3, Theorem 2.2]).

The positivity of the coefficient function $p$ places severe restrictions on the behavior of the nonoscillatory solutions of $(E+)$.

We have the following results concerning $(E+)$.

LEMMA 2.1. If $V$ is a solution of (E+) satisfying

$$
\mathrm{V}_{\mathrm{m}} \geq 0, \Delta \mathrm{V}_{\mathrm{m}} \leq 0, \Delta^{2} \mathrm{v}_{\mathrm{m}}>0
$$

for some integer $m>k \geq 1$, then

$$
\mathrm{v}_{\mathrm{k}}>0, \Delta \mathrm{v}_{\mathrm{k}} \leq 0, \Delta^{2} \mathrm{v}_{\mathrm{k}}>0
$$

for each $1 \leq \mathrm{k}<\mathrm{m}$.

PROOF. We show the lemma true for $k=m-1$. Note that $\Delta^{3} v_{m-1}=\Delta\left(\Delta^{2} v_{m-1}\right)=$ $-\mathrm{P}_{\mathrm{m}-2} \mathrm{~V}_{\mathrm{m}} \leq 0$. Thus $\Delta^{2} \mathrm{v}_{\mathrm{m}} \leq \Delta^{2} \mathrm{~V}_{\mathrm{m}-1}$, and we find $\Delta^{2} \mathrm{~V}_{\mathrm{m}-1}>0$. Similarly, $\Delta^{2} \mathrm{v}_{\mathrm{m}-1}>0$ implies $\Delta \mathrm{V}_{\mathrm{m}-1}<0$, which in turn implies $\mathrm{V}_{\mathrm{m}-1}>0$. Therefore the result holds for $\mathrm{k}=\mathrm{m}-1$. Repeating this process for each $1 \leq \mathrm{k}<\mathrm{m}-1$ proves the lemma.

THEOREM 2.2. If $V$ is a nonoscillatory solution of (E+) then either

$$
\mathrm{V}_{\mathrm{n}} \Delta \mathrm{v}_{\mathrm{n}} \Delta^{2} \mathrm{v}_{\mathrm{n}} \neq 0, \operatorname{sgn} \mathrm{v}_{\mathrm{n}}=\operatorname{sgn} \Delta^{2} \mathrm{~V}_{\mathrm{n}} \neq \operatorname{sgn} \Delta \mathrm{V}_{\mathrm{n}},
$$

for each $n \geq 1$, of

$$
\mathrm{V}_{\mathrm{n}} \Delta \mathrm{V}_{\mathrm{n}} \Delta^{2} \mathrm{~V}_{\mathrm{n}} \neq 0, \operatorname{sgnV_{\mathrm {n}}}=\operatorname{sgn} \Delta \mathrm{V}_{\mathrm{n}}=\operatorname{sgn} \Delta^{2} \mathrm{v}_{\mathrm{n}}
$$

for all sufficiently large $n$.

PROOF. Assume that $V$ is a nonoscillatory solution of (Et), where without loss of generality $v_{n}>0$ for each $n \geq N$. Note that $\Delta^{3} v_{n}=\Delta\left(\Delta^{2} v_{n}\right)=-P_{n-1} v_{n+1}<0$ for al? $\mathrm{n} \geq \mathrm{N}$ hence $\Delta^{2} \mathrm{~V}_{\mathrm{n}}$ is decreasing and is eventually one sign. It follows that $M$ exists, $M \geq N$ for which $\Delta V_{n}$ and $\Delta^{2} V_{n}$ are sign definite, for all $n \geq M$. Hence $v_{n} \Delta v_{n} \Delta^{2} v_{n} \neq 0$, for every $n \geq M$. The following cases must be considered:

$$
\begin{aligned}
& \mathrm{V}_{\mathrm{n}}>0, \Delta \mathrm{V}_{\mathrm{n}}<0, \Delta^{2} \mathrm{~V}_{\mathrm{n}}>0, \mathrm{n} \geq \mathrm{M} \\
& \mathrm{V}_{\mathrm{n}}>0, \Delta \mathrm{V}_{\mathrm{n}}>0, \Delta^{2} \mathrm{~V}_{\mathrm{n}}>0, \mathrm{n} \geq \mathrm{M} \\
& \mathrm{V}_{\mathrm{n}}>0, \Delta \mathrm{V}_{\mathrm{n}}<0, \Delta^{2} \mathrm{~V}_{\mathrm{n}}<0, \mathrm{n} \geq \mathrm{M} \\
& \mathrm{V}_{\mathrm{n}}>0, \Delta \mathrm{V}_{\mathrm{n}}>0, \Delta^{2} \mathrm{~V}_{\mathrm{n}}<0, \mathrm{n} \geq \mathrm{M} .
\end{aligned}
$$

The cases (c) and (d) are clearly impossible since $\Delta^{j} v_{n} \Delta^{j+1} v_{n}>0$ for all $n$ sufficiently large implies that $s g n \Delta^{j-1} V_{n}=s g n \Delta^{j} V_{n}$ eventually. To complete the proof, apply Lemma 2.1 to the case (a).

The existnece of a solution $V$ of $(E+)$, satisfying the conditions (2.1) is established in [3].

Denote by (S-) the solution space of (E-) and (S+) the solution space of (E+). For $(U, V) \varepsilon(S-) \times(S+)$ define

$$
F_{n}=F\left[U_{n}, V_{n}\right]=U_{n+1} \Delta^{2} V_{n+1}-\Delta U_{n} \Delta V_{n+1}+V_{n+1} \Delta^{2} U_{n} .
$$


It is easy to verify. The function defined by (2.3) is a constant determined by the initial values of $U$ and $V$, hence, $F_{n}$ represents the discrete LaGrange bilinear concomitant for solutions of $(E-)$ and $(E+)$. Using (2.3), proofs of the following two results can be modeled after the analogous results appearing in [3].

THEOREM 2.3. Suppose that $U$ is a nonoscillatory solution of (E-). If (E+) has an oscillatory solution, then there are two independent oscillatory solutions of (E+) that satisfy

$$
\Delta\left(\frac{\Delta \mathrm{V}_{\mathrm{n}}}{\mathrm{U}_{\mathrm{n}}}\right)+\left(\frac{\Delta^{2} \mathrm{U}_{\mathrm{n}-1}}{\mathrm{U}_{\mathrm{n}} \mathrm{U}_{\mathrm{n}+1}}\right) \mathrm{V}_{\mathrm{n}+1}=0 .
$$

COROLLARY 2.4. If (Et) has an oscillatory solution, there exists a basis for the solution space $(\mathrm{S}+$ ) consisting of $k$ nonoscillatory solutions and $3-k$ oscillatory solutions for $k=0,1$.

REMARK. Since the nodes of linearly independent solutions of (2.4) separate each other, and those of linearly dependent solutions coincide, it follows that solutions of (2.4) are oscillatory. See for example, Fort [3, p.221].

We conclude this section with the following easily verifiable result.

LEMMA 2.5. The graph of a sequence $X=\left\{x_{n}\right\}$ is defined by

$$
G\left(r, x_{n}\right)=\left(\Delta x_{n}\right)(r-n)+x_{n}, n \leq r \leq n+1, n \geq 1 .
$$

Let $\mathrm{Y}$ be a sequence. Then,

(i) $G\left(r,\left(a X_{n}+b Y_{n}\right)\right)=a G\left(r, X_{n}\right)+b G\left(r, Y_{n}\right)$ $\mathrm{n} \leq \mathrm{r} \leq \mathrm{n}+1, \mathrm{n} \geq 1$, where $\mathrm{a}$ and $\mathrm{b}$ are constants.

(ii) If $\Delta \mathrm{x}_{\mathrm{m}} \geq 0(\leq)$ for some integral $\mathrm{m}$, then

$$
x_{m} \leq G\left(r, x_{m}\right) \leq x_{m+1} \quad\left(x_{m} \geq G\left(r, x_{m}\right) \geq x_{m+1}\right) .
$$

(iii) If $x_{n} \geq 0(\leq 0)$ for each $n$, then $G\left(r, x_{n}\right) \geq 0(\leq 0)$ for each $r$.

\section{MAIN RESULT.}

In case $(\mathrm{E}+)$ has oscillatory solutions, our main result shows that more stringent requirements are imposed on the nonoscillatory solutions of (E+), than those imposed by Theorem 2.2. We will show that solutions satisfying relations (2.2) cannot be "Introduced" into the solution space (S+) without "forcing" out all the oscillatory solutions.

THEOREM. A necessary and sufficient condition for (E+) to have oscillatory solutions is that for any nonoscillatory solution $V$, the relations (2.1) are satisfied.

PROOF. The sufficiency is clear. If every nonoscillatory solution $V$ satisfies the relations (2.1), by Lemma $2.5 \mathrm{G}\left(\mathrm{r}, \mathrm{V}_{\mathrm{n}}\right)$ for such a solution is of one sign for each $n \geq 1$. It follows that any solution with a node is oscillatory; thus we see that initial values can be used to construct oscillatory solutions of $(E+)$. To prove the necessity, suppose that $(E+)$ has an oscillatory solution, and that (E+) has a solution $Z$ satisfying the relations (2.2). By Corollary 2.3 and the above remark, there exists a basis for ( $S+$ ) consisting of one nonoscillatory solution $R$ satisfying conditions (2.1) and two oscillatory solutions $S$ and $T$, with every linear combination of $S$ and $T$ oscillatory. Now $Z_{n}=C_{1} R_{n}+C_{2} S_{n}+C_{3} T_{n}$ where $C_{1}, C_{2}, C_{3}$ are scalars, 
$c_{1}^{2}+c_{2}^{2}+c_{3}^{2} \neq 0$. Conditions (2.2) imply $\lim _{n \rightarrow \infty}\left|z_{n}\right|=\infty$. Let $\left\{r_{1}\right\}$ be an increasing sequence of nodes of $\left\{\mathrm{C}_{2} \mathrm{~S}_{n}+\mathrm{C}_{3} \mathrm{~T}_{n}\right\}$. Then at each $\mathrm{r}_{i}$

$$
G\left(r_{i}, z_{n}\right)=C_{1} G\left(r_{i}, R h^{\prime}\right.
$$

The left member of (2.5) is bounded as $i \rightarrow \infty$. This contradiction completes the proof of the theorem.

In conclusion we present an example showing that it is possible for every solution of (Et) to be nonoscillatory. The relations (2.2) are satisfied by the funciton $V$ defined by $v_{n}=n+2^{-n+1}$. It is easily seen that $v$ is a solution of

$$
\Delta^{3} v_{n}+\frac{1}{\left.4\left[(n+1) 2^{n}+1\right)\right]} v_{n+1}=0 \quad
$$

Consequently every solution of (E) is nonoscillatory.

ACKNOWLEDGEMENT. This research was partially supported by Texas Southern University Faculty Research \#16512.

\section{REFERENCES}

1, LAZER, A. C., The behavior of solutions of the differential equation $y^{\prime \prime \prime}+$ py' $+q y=$ 0 , Pacific J. Math., 17 (1966), 435-466.

2. FORT, T., Finite Differences and Difference Equations in the real Domain, Oxford University Press, London, 1948.

3. SMITH, B., Oscillatory and asymptotic behavior in certain third order difference equations, to appear, Rocky Mt. J. Math. 


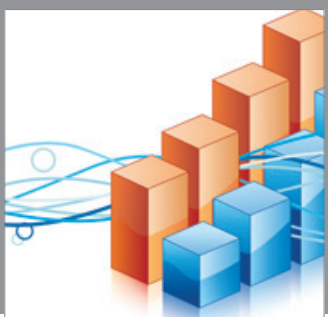

Advances in

Operations Research

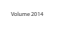

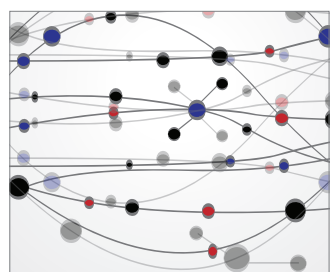

\section{The Scientific} World Journal
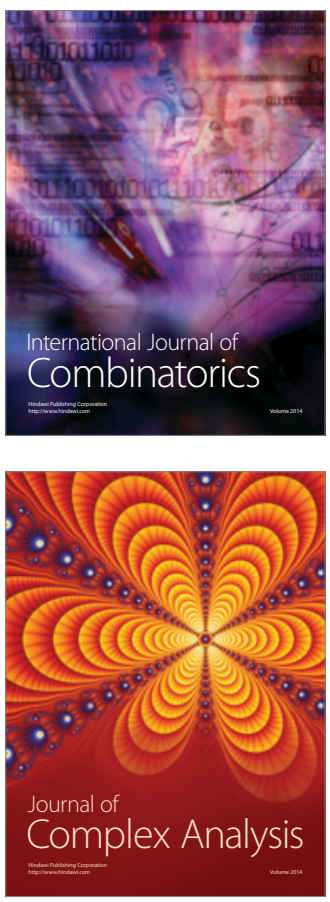

International Journal of

Mathematics and

Mathematical

Sciences
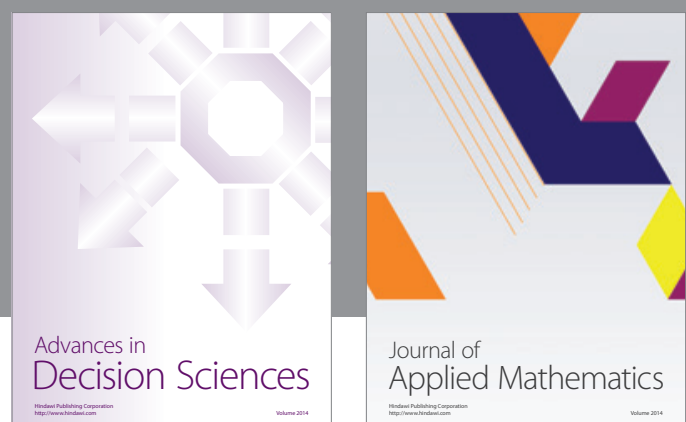

Journal of

Applied Mathematics
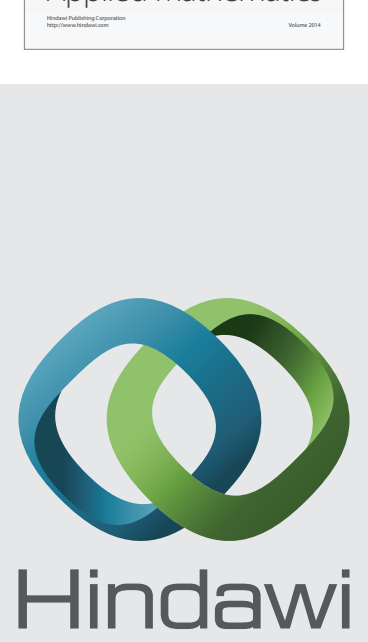

Submit your manuscripts at http://www.hindawi.com
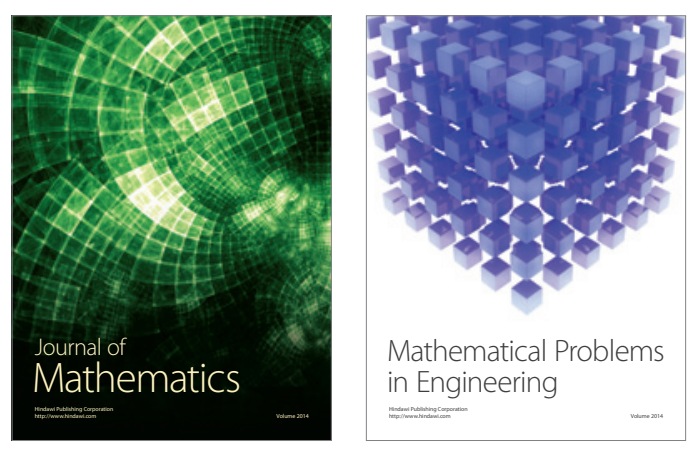

Mathematical Problems in Engineering
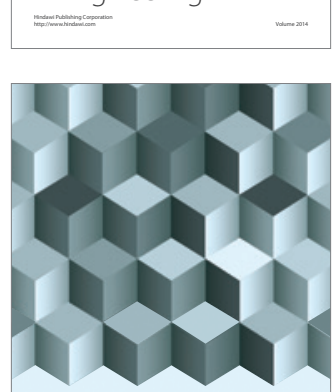

Journal of

Function Spaces
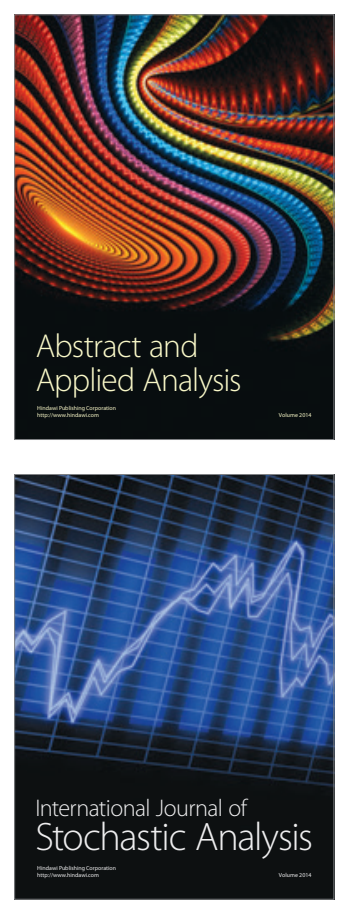

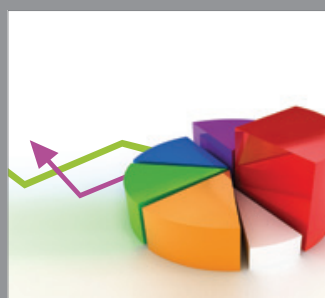

ournal of

Probability and Statistics

Promensencen
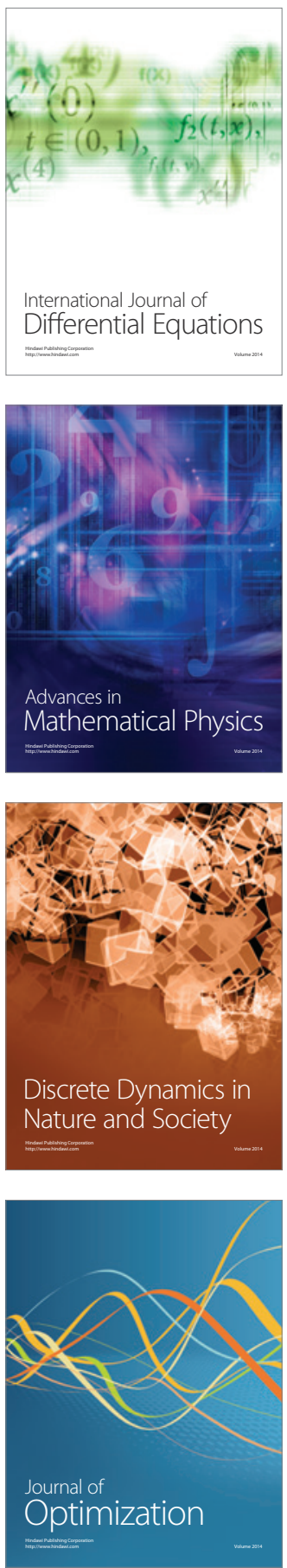